\title{
INFLUENCE OF ANNEALING ON STRUCTURE AND FATIGUE PROPERTIES OF MICROALLOYED STEEL
}

\begin{abstract}
Advanced microalloyed steels (HSLA steels) contain microstructural components whose mechanical properties can be altered by exposure to elevated temperatures, for example, in application of welding cycles. The objective of this paper is to identify the relative influence of annealing (annealing at $650^{\circ} \mathrm{C}$ for $25 \mathrm{~min}$ ) on microstructure and fatigue properties variability of HSLA steels. The results obtained in this work suggest that in spite of no or very small positive effect of annealing on the fatigue limit of HSLA steels with no stress concentrator in its presence it can be expected that the annealing has a negative influence either on fatigue crack initiation or fatigue crack growth.

Key words: fatigue strength; crack initiation; fatigue crack growth, low-temperature annealing; pipeline steel; microstructure;
\end{abstract}

\section{Introduction}

Hot rolled steel strips are the most frequently used structural materials. Microalloyed steels (usually named as high strength low alloyed steels) have an indisputable position among them representing about 10 per cent of the world steel production. The principal advantage of these steels is the possibility to achieve high strength levels without increasing the amount of alloying elements. The required mechanical properties are achieved by means of controlled rolling where the mastering of precipitation processes (of the elements $\mathrm{Al}, \mathrm{Ti}, \mathrm{Nb}, \mathrm{V}, \mathrm{Zr}$ ) during deformation and cooling from finishing temperature is of primordial importance. This process enables to use the four basic strengthening mechanisms - solid solution strengthening, dislocation strengthening, microstructural strengthening and precipitation strengthening. Usually 70 percent of the yield stress value is due to grain refinement (the finishing rolling temperatures play here a deciding role) and precipitation (the coiling temperatures play here a deciding role). Using of all four strengthening mechanisms at the same composition it is possible to obtain twofold to threefold higher values of yield stress when compared to conventional steels. This enables a significant weight reduction of the projected structures at a cost reduction of about 25 per cent [1-3]. HSLA steels are world-wide used for such structural applications as tubes, boilers, pressures vessels, bridges, ships, automotive industry, for welded machine parts. Structural materials are often exposed to cyclical changes of temperature or stress (eventually of both) being the primary cause of failure in structural applications.

The selection of a material with optimal properties is significantly influenced by its resistance to cyclic loading and the traditional criterion of the selection is the fatigue limit $\left(\sigma_{-1}\right)$. An approximate estimation of the fatigue limit of steels loaded by alternating symmetric cycling $\left(R=\sigma_{\min } / \sigma_{\max }=-1\right)$ is about the halve of its tensile strength $\left(\sigma_{-1} / R_{m}=0,5\right)$. The fatigue limit mea- sured both on smooth and notched specimens increases with their strength but the differences between $\sigma_{-1}$ measured on steels with different strengths decrease with increasing level of stress concentration. It is not unusual that fatigue limits measured on poorly machined or not machined welded joints are totally independent on strength and are in the range of 100-200 MPa [4]. Besides welded joints other stress concentrators may be encountered which shorten the initiation stage of the fatigue crack in such an extent that the propagation stage may dominate the life of the structure. For that reason besides the fatigue limit the loading level below which the existing cracks do not propagate i.e. the threshold value of stress intensity factor range $\left(\Delta K_{0}\right)$ has to be considered as an important factor of fatigue resistance. It is clear that depending on the structural project and the exploitation of the structure either the initiation stage or the propagation stage will dominate and, therefore, it is important that the fatigue resistance be evaluated separately in the different stages. Among the advantages of the introduction of rolling.

HSLA steels by a controlled schedule of rolling and cooling was the possibility to achieve the required mechanical properties without the necessity of subsequent normalization. In spite of that in order to optimize some sheet and strip properties sometimes an additional heat treatment is incorporated into the processing route consisting of annealing at different temperatures. Annealing below the Ac1 temperature is advantageously used for coils where the measured strengths were higher than the required values or the Charpy impact energy was lower than specified.

The aim of this contribution is to evaluate the influence of low temperature annealing on changes in the fatigue resistance of HSLA steels microalloyed on the basis of $\mathrm{Nb}, \mathrm{Nb}-\mathrm{V}, \mathrm{Nb}-\mathrm{V}-\mathrm{Zr}$, both in the crack initiation and crack propagation stages.

\footnotetext{
* Gejza Rosenberg

Faculty of Metallurgy, Technical University of Košice, Letná 9, 04200 Kosice, Slovakia, E-mail: Gejza.Rosenberg@tuke.sk
} 


\section{Material and Experimental Procedures}

\section{Material}

Four commercially produced HSLA steels microalloyed on the basis of $\mathrm{Nb}$ (steel $\mathrm{B}$ ), $\mathrm{Nb}+\mathrm{V}$ (steel $\mathrm{D}$ and 6) and $\mathrm{Nb}+\mathrm{V}+\mathrm{Zr}$ (3) respectively were used for the experiments. Table 1 shows the steels compositions.

The steels designated by B and D had in comparison to steels 3 and 6 higher carbon content but, on the other hand, the carbon equivalents $\left(\mathrm{C}_{\text {ekv. }}=\mathrm{C}+\mathrm{Mn} / 6+(\mathrm{Cr}+\mathrm{Mo}+\mathrm{V}) / 5+(\mathrm{Ni}+\mathrm{Cu}) / 15\right)$ of steels $\mathrm{B}$ and 3 on one side and $\mathrm{D}$ and 6 on the other side were comparable $\left(\mathrm{C}_{\mathrm{ekv}}=0,28\right.$ and $\mathrm{C}_{\mathrm{ekv}}=0.33$, respectively $)$. The steel plates were rolled by similar controlled rolling schedules, being the finishing temperatures rolling always in the ranges: $t_{d o v}=835-850$ ${ }^{\circ} \mathrm{C}$ and $t_{\text {nav }}=570-580{ }^{\circ} \mathrm{C}$, respectively, while still maintaining tdov $t_{\text {nav. }}=260$ to $270{ }^{\circ} \mathrm{C}$. The thickness of the rolled plates was the same, $8 \mathrm{~mm}$. The specimens were cut perpendicularly and parallel to the rolling direction, with dimensions of $60 \times 150 \mathrm{~mm}$. The mechanical properties were measured in the as delivered condition, without surface machining. Both from the un-annealed material as well as from a set of selected cut pieces annealed for $650^{\circ} \mathrm{C} /$ 25 min fatigue test specimens were machined. On the same specimens hardness was also measured.

\section{Fatigue testing}

All fatigue tests were performed at the frequency $f=25 \mathrm{~Hz}$ and stress ratio $R=0.03$ (notched specimens) and $R=-1$ (unnotched specimens). Plane bending fatigue tests were conducted on smooth specimens which in the reduced section had $B=4.1 \pm 0.1 \mathrm{~mm}$ thickness and $W=6 \mathrm{~mm}$ width. The evaluation of the fatigue strength in both unnotched and notched test specimens was done for 107 cycles. The surfaces of all specimens were metallographically ground, polished, and in some cases also etched.

The fatigue crack initiation and propagation behavior was investigated on notched specimens in three-point bending at a stress ratio $R=0.03$ and frequency of $f=25 \mathrm{~Hz}$. The data were obtained by testing single-edge-notched (SEN) specimens of $W=20 \mathrm{~mm}$ (working length $L=4 \mathrm{~W}$ ) width and $\mathrm{B}=6 \mathrm{~mm}$ thickness containing a $5.0 \mathrm{~mm}$ deep electrospark-produced notch. The notch tip radius were $\rho=0.06 \mathrm{~mm}$ for FCG or $\rho=0.2 \mathrm{~mm}$ for fatigue crack initiation experiments.

All specimens were precracked over a length of $\approx 0.7 \mathrm{~mm}$. After crack initiation in the samples at the level of $\Delta K \approx 6$ to 8 $\mathrm{MPam}^{1 / 2}$ the loading was gradually decreased or maintained at a constant level of $\Delta K$ with the aim to determine the threshold value of stress intensity factor range $\left(\Delta K_{t h}\right)$, defined by the decrease of the FCG below the level of $d a / d N=2 \times 10^{-7} \mathrm{~mm} /$ cycle. For both tested conditions minimally three specimens were used for each structural state and direction. Only the FCG data measured at increasing value of $\Delta K$ were recorded. The crack length was monitored using an optical microscope and potential drop technique. The loading level was increased in such a way that each additional increase in the $\Delta K$ value occurred only after the FCG for the length corresponding to minimally three-fold of the PZ size. Fracture surfaces were examined by a scanning electron microscope.

\section{Experimental Results and Discussion}

The mechanical properties measured on specimens cut parallel to rolling direction in the as -delivered condition are listed in Table 2.

Mechanical properties and mean grain sizes

Table 2 of tested steels

\begin{tabular}{|c|c|c|c|c|c|c|c|}
\hline Steel & $\begin{array}{c}R_{p 02} \\
\mathrm{MPa}\end{array}$ & $\begin{array}{c}R_{m} \\
\mathrm{MPa}\end{array}$ & $\begin{array}{c}R_{p 02} / R_{m} \\
\mathrm{MPa}\end{array}$ & $\begin{array}{c}A_{5} \\
\%\end{array}$ & $\begin{array}{c}Z \\
\%\end{array}$ & $\begin{array}{c}K C V 2 \\
\mathrm{~J} . \mathrm{cm}^{-2}\end{array}$ & $\begin{array}{c}d_{F} \\
\mu \mathrm{m}\end{array}$ \\
\hline $\mathrm{B}$ & 468 & 582 & 0.804 & 26.4 & 67.1 & 171 & 6.8 \\
\hline $\mathrm{D}$ & 482 & 598 & 0.806 & 23.2 & 58.6 & 128 & 5.8 \\
\hline 6 & 518 & 615 & 0.842 & 26.5 & 67.4 & 165 & 5.4 \\
\hline 3 & 533 & 629 & 0.847 & 27.1 & 69.4 & 192 & 4.9 \\
\hline
\end{tabular}

Comparing the data in Table 1 it is clear that in spite of the different finishing rolling and coiling temperatures these steels have significantly different mechanical properties. The results in Table 1 show that steel 3 has the highest levels of yield stress and tensile strength also the highest elongation, reduction of area and Charpy impact energy. Steels B and 6 have their strength and plasticity about on the same level. The steel D significantly differs from the others by about 15 per cent lower values of elongation, reduction of area and by 25 per cent lower impact energy.

The microstructural analysis was conducted on sections in the three principal directions in relation to the rolling direction. The microstructures of the investigated steels in the as-delivered condition (the polished planes of the metallographical specimens being parallel with the surface of the strips) are documented on Fig. 1

Chemical compositions of the materials used (mass \%)

Table 1.

\begin{tabular}{|c|c|c|c|c|c|c|c|c|c|}
\hline Steel & $\mathrm{C}$ & $\mathrm{Mn}$ & $\mathrm{Si}$ & $\mathrm{P}$ & $\mathrm{S}$ & $\mathrm{Al}$ & $\mathrm{Nb}$ & $\mathrm{V}$ & $\mathrm{Zr}$ \\
\hline $\mathrm{B}$ & 0.090 & 1.15 & 0.33 & 0.014 & 0.008 & 0.037 & 0.035 & - & - \\
\hline $\mathrm{D}$ & 0.100 & 1.36 & 0.28 & 0.015 & 0.008 & 0.054 & 0.022 & 0.032 & - \\
\hline 6 & 0.070 & 1.48 & 0.13 & 0.010 & 0.009 & 0.040 & 0.035 & 0.055 & - \\
\hline 3 & 0.070 & 1.23 & 0.28 & 0.012 & 0.007 & 0.058 & 0.070 & 0.030 & 0.06 \\
\hline
\end{tabular}


while the mean grain values are listed in Table1. Generally, the microstructures were very heterogeneous consisting of larger irregular ferritic grains combined with significantly smaller and more or less polyhedric grains. Locally the steels 3,6 and B to a limited extent exhibited acicular ferrite while in the steel B also ferrite with Widmanstätten morphology. In all of the investigated steels except B grains larger than 10 um were present only sporadically the preponderant grain size range was 4 to $8 \mathrm{um}$. In the steel B in some areas grains of the size about 15 um were observed more frequently i.e. the double of the mean grain size. Except of the stee D all others exhibited on the metallographical sections perpendicular to the strip surface and principally in the plane parallel to the rolling direction elongated grains. This direction dependence of the grain size was clearly detectable in steel B but especially was pronounced only in steels 3 and 6 . A detailed metallographical analysis of steels 3 and 6 showed that besides the finer grains of steel 3 they are very similar microstructurally, i.e. by morphology and type of the microstructural constituents. In spite of its mechanical properties steel D exhibited the less heterogeneous microstructure with frequent occurrence of small polyhedric grains located along the grain boundaries of the larger more acicular grains. The perlite in this steel had a more disperse morphology and along the grain boundaries frequently were observed carbides or particles of other phases, sometimes forming a continuous envelop.
The precipitation was investigated by means of carbon extraction replicas in a transmission electron microscope (TEM). From Figs. 2-B to 2-Da which document the as delivered condition it is clear that the sequence with the highest precipitation degree is 2-D, 2-3 and 2-6 respectively, while the lowest degree belongs to steel 2-B, which was micro-alloyed only with 0.03 per cent of $\mathrm{Nb}$. The particles along the grain boundaries were observed mainly in steel 3 and steel 6 . The particles in steel 3 had thickness of $100 \mathrm{~nm}$, exceptionally $200 \mathrm{~nm}$ (Figs. 2-3a) and in steel D they had a thickness above $500 \mathrm{~nm}$ (Fig. 2-Da).

The hardness values measured on annealed specimens listed in Table 2 indicate the highest hardness increase was registered in steels 3 and 6 . It confirms the expectation since these steels contained the highest a microalloying addition which is the principal precondition of a successful precipitation hardening. It is supposed that the precipitates were carbides and principally carbonitrides of vanadium for which the highest precipitation rates is considered to be about $600^{\circ} \mathrm{C}$ [1]. This affirmation is supported by the fact that steel $\mathrm{B}$ which did not contain vanadium showed no additional strengthening by annealing (Table 3 ).

On the other hand, the TEM observation of carbon extraction replicas confirmed that annealing caused an increase in the density of soft precipitates not only in steels 3,6 and D but also in steels
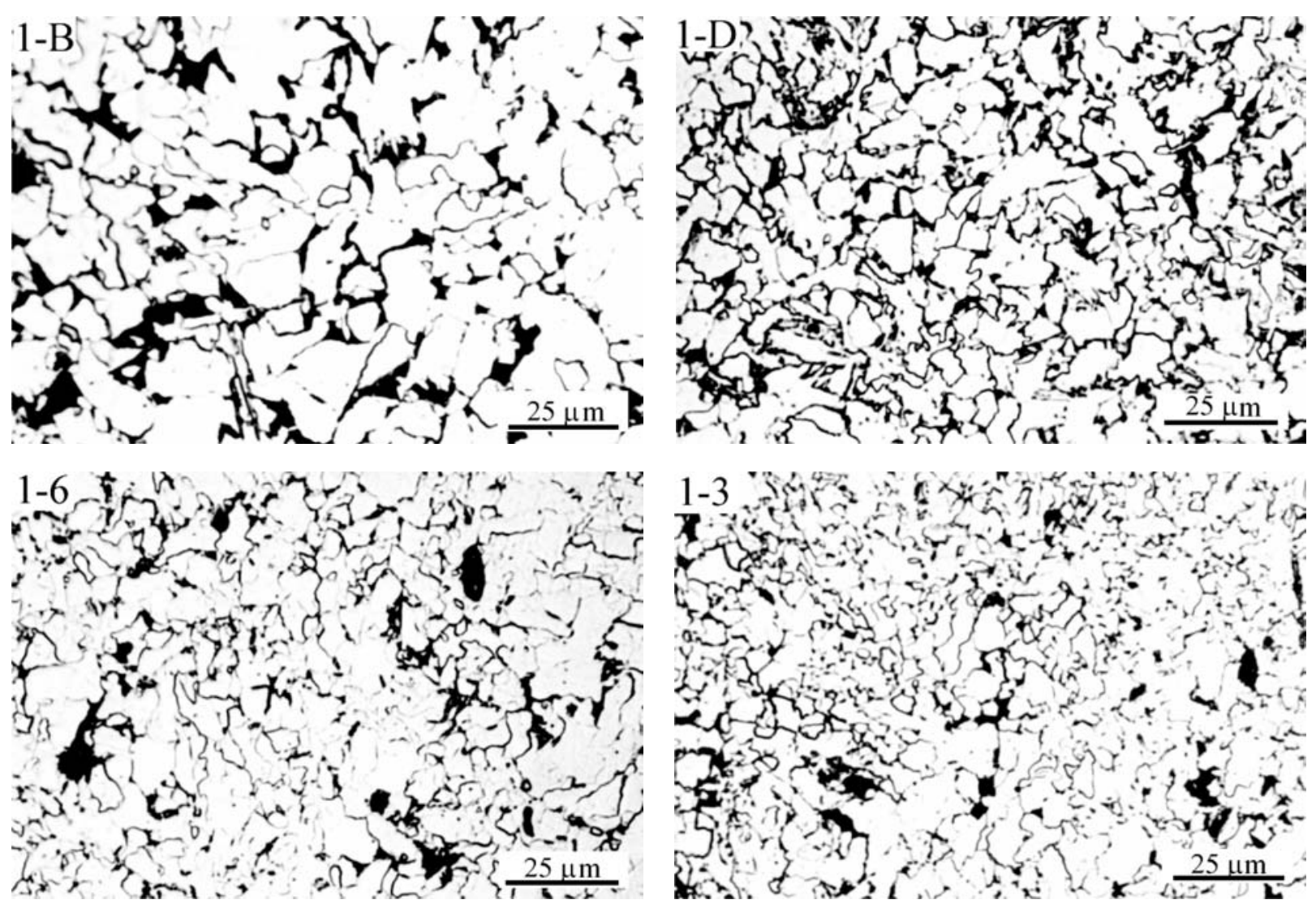

Fig. 1 Microstructure of HSLA steels B, D, 6 and 3 
Test results of fatigue limits and hardness before - after annealing

\begin{tabular}{|c|c|c|c|c|c|}
\hline Steel & $\begin{array}{c}H B \\
\text { delivered }\end{array}$ & $\begin{array}{c}H B \\
\text { annealed }\end{array}$ & $\begin{array}{c}\sigma_{0} \\
\mathrm{MPa}\end{array}$ & $\sigma_{0} / R_{m}$ & $\sigma_{0} / H B$ \\
\hline $\mathrm{B}$ & 183 & 184 & 327 & 0.562 & 1.78 \\
\hline $\mathrm{D}$ & 186 & 191 & 317 & 0.530 & 1.66 \\
\hline 6 & 191 & 203 & 335 & 0.545 & 1.65 \\
\hline 3 & 195 & 205 & 341 & 0.542 & 1.88 \\
\hline
\end{tabular}
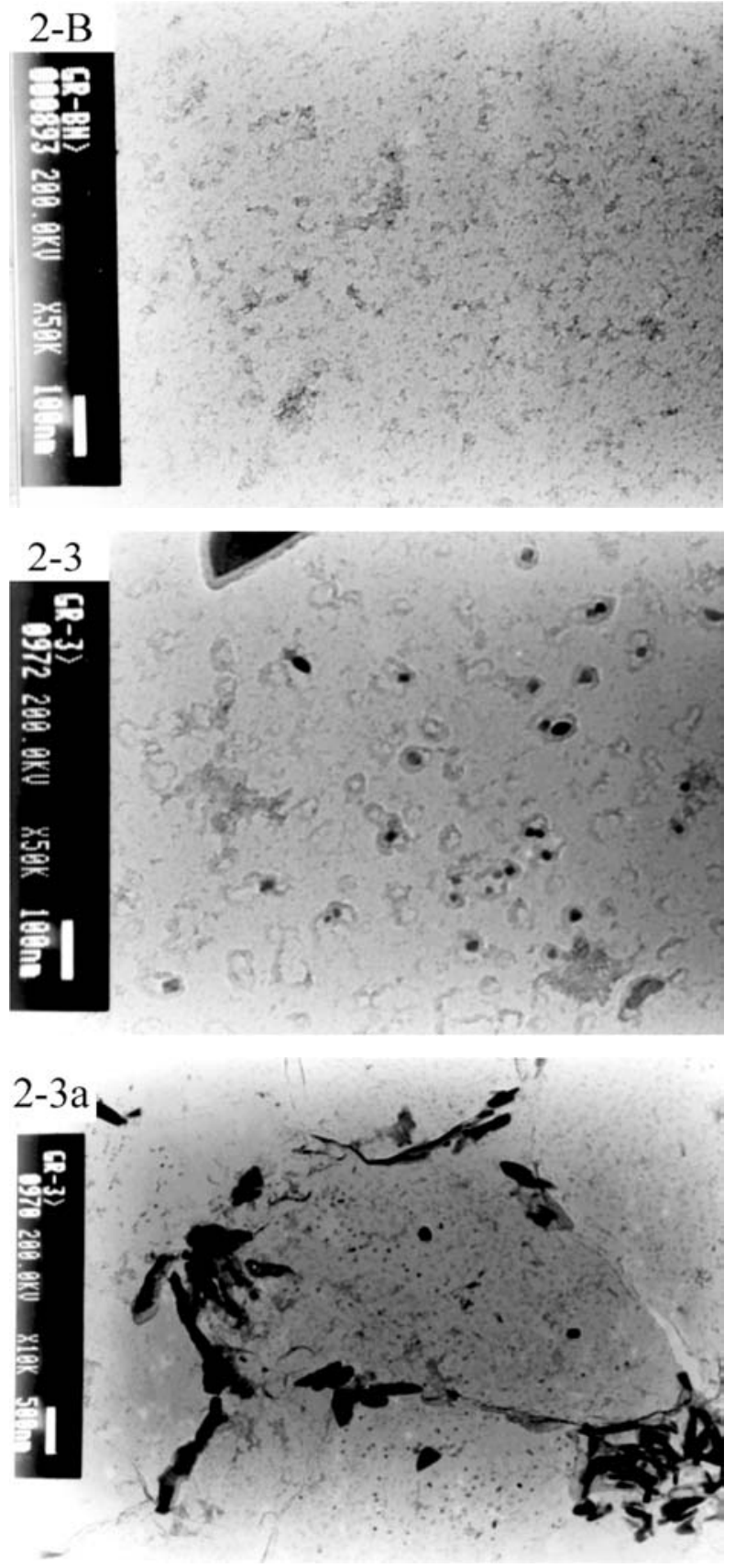

Tab. 3
B. It has to be assumed that probably the precipitates AlN also participated in the precipitation process, having the maximal precipitation rate of about $700{ }^{\circ} \mathrm{C}$ or rather niobium carbonitrides, the precipitation of which at $600{ }^{\circ} \mathrm{C} / 10 \mathrm{~min}$ resulting in a hardness increase of $20 \mathrm{HV}$ was observed also in [5].

The fatigue limit of smooth specimens was investigated only in the annealed condition and on specimens cut parallel to rolling direction, Table 3 . This table also contains the calculated ratio $\sigma_{-1} / R_{m}$, where $R_{m}$ means the tensile strength in un-annealed con-
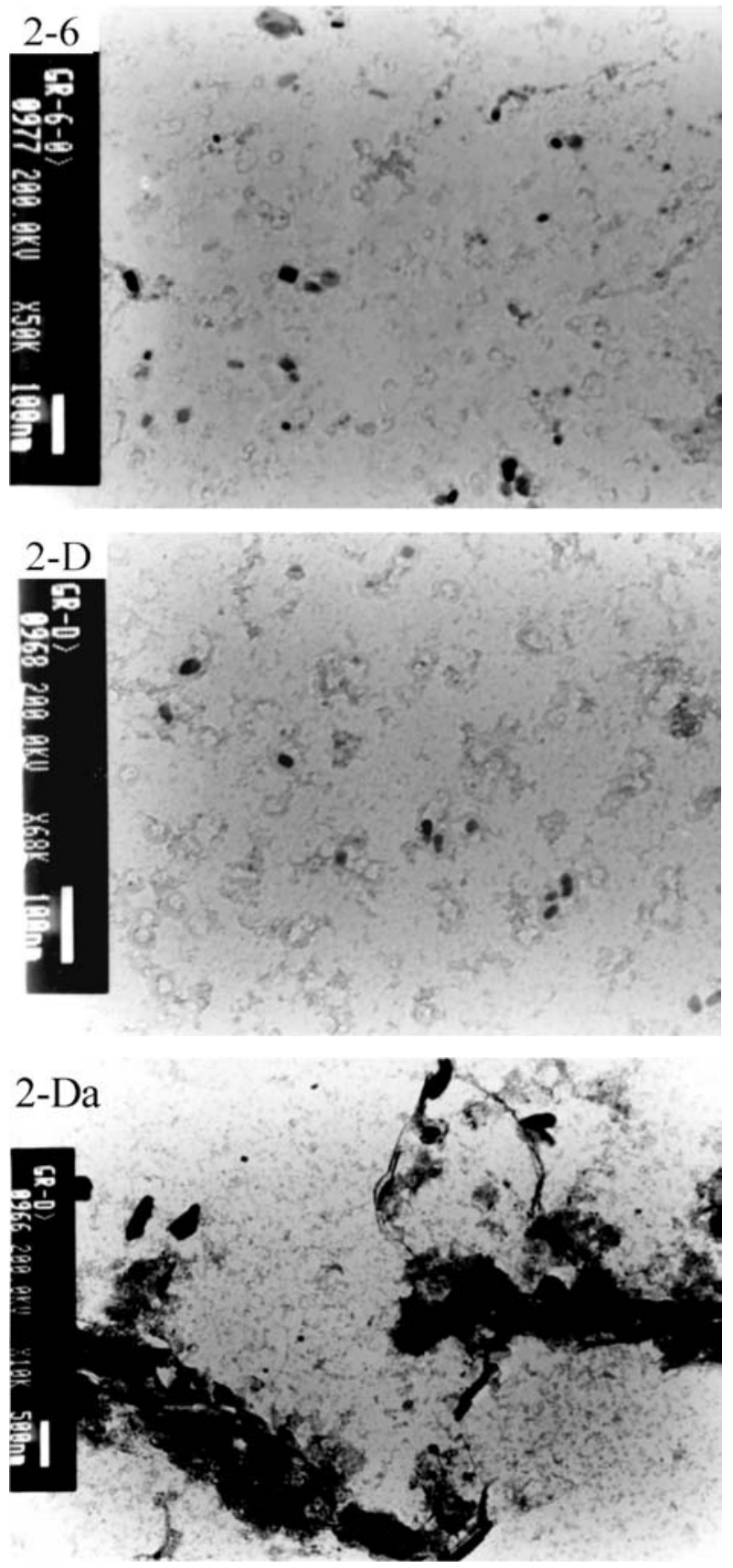

Fig. 2 TEM images of carbon extraction replicas for HSLA steels B, 6, 3 and D 
dition from Table 1. The small difference in hardness between annealed and not annealed specimens and the observation that annealing increases the yield stress [5] leads us to suppose that the $\mathrm{Rm}$ values did not change by annealing. The relatively high values of the $\sigma_{-1} / R_{m}$ ratio in the range 0.53 to 0.56 are in agreement with the value $\sigma_{-1} / R_{m}=0.54$ measured in another HSLA steel group [6]. Therefore, we suppose that if the annealing had any influence on $\sigma_{-1}$, so it was only slightly positive as a result of hardness increase.

The influence of annealing was clearly observed also by light microscopy. In steels 3, 6 and B the acicular ferrite disappeared or its amount was significantly reduced along with the decomposition of lamellar perlite resulting in the appearance of its less disperse modification. A general statement can be done that annealing resulted in a decrease of the marked microstructural heterogeneity observed in the as -delivered condition. In steel D the microstructural changes were minimal. The most pronounced changes occurred in steels 3 and 6 in which along with the above mentioned features a significant reduction of the elongated grain shape due to rolling direction was observed, being this more pronounced in the central area of the specimens.

The results of microscopical analysis showed a good correlation with the measured values of fatigue crack initiation resistance on notched specimens and crack propagation rate changes at a given level of stress intensity amplitude $(\Delta K)$ including the threshold value $\left(\Delta K_{0}\right)$. The results are resumed in Table 4 .

It can be deduced from Table 4 that fatigue resistance anisotropy occurred only in steels 3 and 6 due to elongated grains in the rolling direction. When cracks grew perpendicularly to the elongated grains the crack propagation rates were significantly lower as in the parallel direction. The crack propagation rate values measured on specimens with cracks oriented parallel to the rolling direction in steels 3 and 6 were the same as in steel B (both on specimens parallel and perpendicular to the rolling direction).

The lowest value of the fatigue crack growth (FCG) resistance was measured in steel $\mathrm{D}$ in which independently on the rolling direction the threshold values $\Delta K_{t h}$ were by 15 per cent lower when compared to steel B. In comparison with steel B the largest difference (as far as 100 per cent) in FCG rate was observed in the range above the threshold value, but also at a loading level of $\Delta K=20 \mathrm{MPa} \cdot \mathrm{m}^{1 / 2}$ were difference in the FCG rates marked. The highest threshold values $\Delta K_{t h}$ and the lowest crack propagation rates at a given level of loading were observed in steels 3 and 6 , when the direction of crack growth was perpendicular to the rolling direction. In comparison to steel $\mathrm{D}$ cracks grow in this case in the range above the threshold value four times more slowly and at a loading level of $\Delta K=20 \mathrm{MPa} \cdot \mathrm{m}^{1 / 2}$ three times more slowly while the threshold values $\Delta K_{t h}$ are about 50 per cent higher. Attention has to be given to the fact that the threshold value for crack initiation $K_{t h, \rho=0,2}$ in steels 3 and 6 is lower than the threshold value for crack propagation. This apparently contradictory experimental result can be explicated by the well-known effect of premature crack closure, which occurs more intensively in specimens with a longer fatigue crack [7]. From Table 3 it is clear that the annealing had either no effect on crack growth (steel B) or its influence was negative. Differently from steel $\mathrm{D}$, where the decrease of resistance to fatigue crack growth as well as the decrease of the resistance to crack initiation on notched samples can be considered as insignificant, in steels 3 and 6 a significant degradation of both of the above mentioned characteristics occurred. These results can be explicated by the effect of annealing on suppression of differences in ferritic grain size in both directions relative to rolling direction. Also the fact that steels B, 3 and 6 in the annealed condition show minimal difference both in the threshold values $\Delta K_{t h, \rho=0,2}, \Delta K_{t h}$ and fatigue crack growth rates expressed by the parameter $d a / d N_{(\Delta K=20}$ is in accordance with the results of the metallographical analysis. The worst properties were observed in steel $\mathrm{D}$ which exhibited even after the annealing cycle the threshold values $\Delta K_{t h, \rho=0,2}$ and $\Delta K_{t h}$ by about 20 per cent lower when compared to all of the investigated steels in this work. Microstructures similar to steel D were observed in other HSLA steels annealed at temperatures below Ac1 for a few hours, but not even in this case a significant deterioration of resistance to FCG growth occurred.

It is well known that besides the finishing rolling and coil temperatures exist also many other factors which in certain circumstances may more or less influence the final steel properties. Among the factors that may significantly influence the final properties already in the early stages of the processing is the casting velocity and casting temperature, the heating temperature of slabs as the thermomechanical conditions of the rolling. The carbon content

Influence of annealing on fatigue crack initiation-growth resistance

Table 4.

\begin{tabular}{|c|c|c|c|c|c|}
\hline Microstructure condition & Steel & Direction to $R D$ & $\Delta K_{t h, \rho=0,2} \mathrm{MPa} . \mathrm{m}^{1 / 2}$ & $d a / d N_{\Delta K=20} \mathrm{~mm} /$ cycles & $\Delta K_{t h} \mathrm{MPa} . \mathrm{m}^{1 / 2}$ \\
\hline \multirow{3}{*}{ Initial condition } & $\mathrm{B}$ & $\mathrm{II}, \perp$ & 6.8 & $3.5 .10^{-5}$ & 5.8 \\
\cline { 2 - 6 } & 6.3 & $\mathrm{II}$ & 6.7 & $3.5 .10^{-5}$ & 5.8 \\
\cline { 2 - 6 } & 6.3 & $\perp$ & 7.2 & $1.5 .10^{-5}$ & 7.6 \\
\cline { 2 - 6 } & $\mathrm{D}$ & $\mathrm{II}, \perp$ & 5.9 & $4.5 .10^{-5}$ & 4.9 \\
\hline \multirow{3}{*}{ Annealed condition } & $\mathrm{B}$ & $\mathrm{II}, \perp$ & 6.8 & $3.5 .10^{-5}$ & 5.8 \\
\cline { 2 - 6 } & 6.3 & $\mathrm{II}$ & 6.8 & $4.0 .10^{-5}$ & 5.8 \\
\cline { 2 - 6 } & 6.3 & $\perp$ & 6.8 & $4.0 .10^{-5}$ & 5.8 \\
\cline { 2 - 6 } & $\mathrm{D}$ & $\mathrm{II}, \perp$ & 5.7 & $4.5 .10^{-5}$ & 4.8 \\
\hline
\end{tabular}


of steel D was 0.1 per cent, which is slightly above the limit where the liquid steel passes through a peritectic reaction during solidification. The transformation of the primary $\delta$-ferrite to austenite is accompanied by segregation processes and precipitation of dendritic shape particles of the size over $500 \mathrm{~nm}$ usually along the $\delta$-ferrite boundaries or along the austenite grain boundaries. During the subsequent stages of hot rolling or cold rolling this segregation structure is deformed but the composition of particles except of the carbon content is maintained as is maintained their effect on embrittlement $[8,9]$. The embrittlement effect of segregation processes along grain boundaries may be pronounced by precipitation of $\mathrm{MnS}$, AlN inclusions or by nitrides and carbonitrides of the microalloying elements $(\mathrm{Nb}, \mathrm{V}, \mathrm{Ti})$, but also by the possible presence of surface active elements ( $\mathrm{Sn}, \mathrm{As}, \mathrm{Sb}, \mathrm{Bi}$ ) and impurities $\mathrm{S}, \mathrm{P}, \mathrm{Cu}$, $\mathrm{Al}$ [9]. Considering the composition of the steel D (Table 2) along with the fact that observed the particles sizes along the grain boundaries in TEM (Fig 2Da) is comparable with the size of particles formed in the peritectic reaction [10], it can be supposed that exactly the segregation processes due to the solidification of the steel $\mathrm{D}$ by peritectic reaction are responsible for the relatively low values of elongation, impact energy and low resistance to fatigue crack initiation and growth observed in notched specimens.

\section{Conclusions}

The general results of the investigation can be summarized as follows:
1. In all of the investigated steels after an annealing at $650{ }^{\circ} \mathrm{C}$ for $25 \mathrm{~min}$ relatively high values of the fatigue limit were measured, with $\sigma_{0} / R_{m}$ ratio in the range 0.53 to 0.56 .

2. It was confirmed that the threshold values of stress intensity factor amplitude for fatigue crack growth $\left(\Delta K_{t h}\right)$ may be higher than the threshold value for crack initiation on notched specimens with a notch root radius $\rho=0.2 \mathrm{~mm}\left(\Delta K_{t h, \rho=0.2}\right)$, i.e. $\Delta K_{t h}>\Delta K_{t h, \rho=0.2}$.

3. The annealing did not show effect on fatigue crack initiation resistance of micro-alloyed steels in specimens with a notch root radius $\rho=0.2$, or insignificant (max.5 per cent) decrease of $\Delta K_{t h, \rho=0.2}$ was found.

4. The annealing caused in most cases a moderate but always detectable decrease in resistance to fatigue crack growth. The effect of annealing was most pronounced in specimens where the cracks grew perpendicularly to the rolling direction, here the threshold values $\Delta K_{t h}$ decreased by more than 20 per cent. In the range above the threshold value up to the loading level $\Delta K=20 \mathrm{MPa} \cdot \mathrm{m}^{1 / 2}$ the measured crack growth rates were twofold higher in the annealed condition than in material that was not annealed.

Dedicated to the memory of Prof. A. Puškár, DrS c., dr. h. c.

\section{References}

[1] http://vanadiumtechnologypartnership.org/

[2] http://www.cbmm.com.br/english/sources/techlib/info/hsconstr/hsconstr.htm

[3] JUHÁR L, BANÍK J.: Final report N. 4 of research project P2-17, November 1998 (in Slovak).

[4] ROSENBERG, G.: Proceedings of the International Welding Conference, Japan-Slovak Welding Symposium, 5-7 March 1996, Vysoké Tatry, str. 327-330.

[5] ZHAO, M-CH. et al.: Difference in the Role of Non-quench Aging on Mechanical Properties between Acicular Ferrite and Ferrite-Pearlite Pipeline Steels, ISIJ International, Vol. 45 (2005), No. 1, pp. 116-120.

[6] ABE, T. et al: Fatigue Behaviour Various Properties HSLA Bar Steels, Transaction ISIJ International, Vol. 22 (1982), pp. B-152.

[7] ROSENBERG, G.: The Size of Plastic Zone and Fatigue Crack Growth Behaviour of three Forms of Ti-6Al-2.5Mo-1.5Cr Alloy, Fatigue \& Fracture of Engineering Materials \& Structures, 21, 1998, pp. 727-739.

[8] http://www.cbmm.com.br/english/sources/techlib/info/thermhot/f_therho.htm

[9] MAYR, M. et al: EPMA Investigation of Segregations in Continuously Cast Steel, AMS, 10, 2004, 55-65]. 